UDC 316.77

LBC 60.524

\title{
EFFECTS OF PR-ACTIVITIES SEGMENT HoReCa ORGANIZATIONS ON CONSUMER BEHAVIOR OF YOUNG PEOPLE: SOCIOLOGICAL ANALYSIS
}

\author{
Irina S. Bocharnikova \\ Astrakhan State University, Astrakhan, Russian Federation
}

\begin{abstract}
Nowadays in the context of new social and economic conditions the social role of consumption in Russian society is growing. Consumer activity of the population acquires new forms. The consumer behavior of young people has become affected by the socio-economic environment. A huge number of various cafes, restaurants and hotels appear in modern cities. Their main customers are young people. The variety of the HoReCa market creates conditions for competition, and a consumer becomes the object producers fight for. The results of quantitative and qualitative researches of PR technologies affecting consumer behaviour of the young are representedin the form of mutually reinforcing materials on the basis of which it is concluded that one of effective way to attract customers is advertising distributed in the Internet, which can attract consumers' attention by helping them to select a suitable product or service. The impact of advertising as a kind of PR technology on young people is explained by exceptional sensitivity and easiness of perception of different values and patterns of behavior by this age category.

The theme of the research is actual as for the whole Russian segment HoReCa as for Astrakhan in particular, as quantity of restaraunts and cafes is rapidly growing nowadays. In this regard the importance of this theme is stipulated by the necessaty of studying modern aspects of consumer behaviour influenced by PR activity of organizations and revealing the peculiarities of this impact on forming consumer behaviour in HoReCa segment.

Key words: consumer behavior, advertising, Internet, PR-technologies, HoReCa (Hotel-Restaurant-Cafe), attraction-getting and agitational power of ads, channels of dissemination of advertising.
\end{abstract}

УДК 316.77

ББК 60.524

\section{ВЛИЯНИЕ РR-ДЕЯТЕЛЬНОСТИ ОРГАНИЗАЦИЙ СЕГМЕНТА НоReCa НА ПОТРЕБИТЕЛЬСКОЕ ПОВЕДЕНИЕ МОЛОДЕЖИ: СОЦИОЛОГИЧЕСКИЙ АНАЛИЗ}

\author{
Ирина Станиславовна Бочарникова \\ Астраханский государственный университет, г. Астрахань, Российская Федерация
}

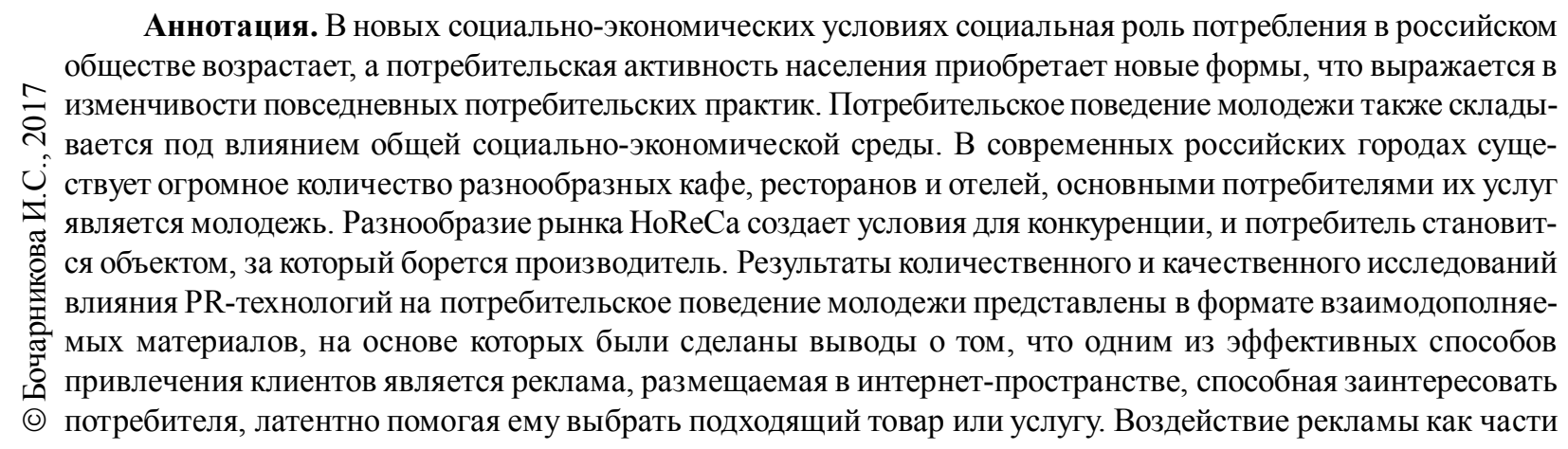


PR-технологий на молодежь объясняется исключительной восприимчивостью и легкостью принятия данной возрастной категорией различных ценностных установок и образцов поведения.

Данная тема исследования актуальна как для всего российского сегмента HoReCa, так и для города Астрахани, так как количество ресторанов и кафе в последнее время стремительно растет. В этой связи актуальность также обусловлена необходимостью исследования современных аспектов потребительского поведения, находящегося под воздействием PR-деятельности организаций, и выявления особенностей данного влияния на формирование потребительского поведения в сегменте HoReCa.

Ключевые слова: потребительское поведение, реклама, Интернет, PR-технологии, организации сегмента HoReCa (Hotel - Restaurant - Cafe), притягательная сила рекламных сообщений, каналы распространения рекламы.

Потребительское поведение, по мнению В.В. Радаева, за последние два десятка лет стало одним из центральных объектов исследования в социологии, ранее в большей степени интересовались процессом труда, трудовыми отношениями, а также конфликтами и отношениями неравенства [10, с. 5]. Так, К. Маркс рассматривает потребление как удовлетворение потребностей человека, T. Веблен как потребление конкретного «праздного класса» - демонстративного (престижного) потребления, Г. Зиммель как «обладание вещью», Дж. Дьюзенберри как «взгляд за соседский забор» - канон «достойного поведения», С. Лэш и Д. Урри как эстетическую рефлексивность.

В последние два десятилетия бо́льшая часть социологических исследований потребительских практик носила культурологический характер, концентрируясь, прежде всего, на символической стороне потребления. Однако в последнее время ситуация изменилась, и в этой области регулярно проводят исследования ведущие российские исследовательские лаборатории и центры, такие как: ВЦИОМ (социально-экономический мониторинг), НИУ ВШЭ(российский мониторинг экономического положения и здоровья населения), ЦИРКОН (мониторинг финансовой активности населения), Левада-центр (уровень жизни населения России, публикуемый в ежегоднике «Общественное мнение») [6, с. 68].

Исследования показали, что современное российское общество включает в себя все черты общества потребления, для которого характерно расширение спектра предоставляемых товаров и услуг. Само потребление обосновывается желаниями и мечтами, а не потребностями человека, проявляется интерес к формированию жизненного стиля и имиджа через потребление товаров и услуг [6, с. 65]. Потребление стало определяющим понятием в современном обществе. Ж. Бодрийяр рассматривает потребление как процесс, в котором систематически происходит манипулирование знаками, целью которого является формирование познаваемого мира при помощи выбранных личностью благ. Потребление это не приобретение каких-либо отдельных материальных благ, а целостность всех используемых вещей и сообщений $[1$, с. 75]. По мнению В.В. Радаева, потребление - это удовлетворение личных потребностей человека посредством использования полезных свойств потребляемого блага, сопряженного с расходованием стоимости данного блага [13, с. 98]. Повышенный интерес, проявляемый научным сообществом к изучению потребительского поведения, носит междисциплинарный характер и определяется рядом причин. Опираясь на экономическую модель потребления, Л.К. Уманская выделяет следующие причины: во-первых, изучение данной темы позволит более точно прогнозировать продажи в качественном и количественном аспектах. Вовторых, изучение потребительского поведения позволит более точно и целенаправленно продумать стратегию маркетинга. В-третьих, при детальном изучении поведения потребителей компании смогут выдвигать более эффективные мероприятия для привлечения определенных покупателей $[13$, с. 60].

Таким образом, можно сказать, что для успешной деятельности на потребительском рынке организации сегмента HoReCa (HotelRestaurant-Cafe), как, впрочем, и все остальные, активно задействуют основные ресурсы, такие как: материально-технический, финансовый, человеческий и информационный. Информационный ресурс занимает особое поло- 
жение, так как в настоящее время информационные технологии развиваются и совершенствуются со стремительной скоростью.

Любая компания стремится создать положительный образ, наладить доброжелательные отношения с потенциальными потребителями, поскольку организация получает прибыль от позитивного восприятия их целевой аудиторией. Для достижения этой цели маркетологи широко используют технологии «public relations (PR)», включающие в себя комплекс мероприятий, нацеленных на воздействие общественного мнения, сконцентрированных на то, чтобы изменить поведение людей и их установки в свою пользу [9, с. 39]. PR-мероприятия формируют положительный имидж организации, а для его успешного создания компании необходим профессионал в области PR, благодаря которому организация может успешно функционировать на рынке. Профессионал создает ценностно-мотивационную среду, формирует стремления, способы мышления, стили поведения, которые присущи в жизненной сфере личности. Современная модель PR делает упор на формирование обратной связи, регулярное информирование потенциальных потребителей о деятельности организации и ее сотрудниках, выработку рекомендаций по выстраиванию траектории успеха компании и маркетинговых коммуникаций [4, с. 46].

PR является социокультурным явлением, которое появилось вследствие социального развития общества. Поэтому здесь вполне актуально рассматривать коммуникационные процессы, которые протекают во всех сферах жизнедеятельности человека. Одним из главных элементов являются средства массовой коммуникации, так как они оказывают большое влияние на сознание потребителей, при этом воздействуя на ценностные ориентации и предпочтения общества. Средства массовой коммуникации формируют представления о различных событиях и товарах. Достижение оптимальных коммуникационных взаимодействий между компаниями и их целевыми группами является основной целью PR-деятельности [11, с. 138].

Далее следует отметить, что PR не только проектирует или исследует общественное мнение, а включает в себя обе эти функции.
При этом они могут выступать как самостоятельно, так и в тесном взаимодействии друг с другом. Если рассматривать PR с точки зрения институционального подхода, то его можно определить как своеобразную систему норм и ценностей. Следовательно, PRкультуру можно трактовать как совокупность ценностей и норм, включенных в PR-деятельность и показывающих уровень потребительского сознания в различных социальных сфеpax, то есть можно говорить о том, что специфическая PR-культура раскрывает сущность общества как социокультурное образование со своими традициями и особенностями [8, с. 269].

Потребительский выбор создается намного раньше, чем совершается самостоятельная покупка. Индивид воспринимает модели потребительского поведения своей первичной группы, которые в свою очередь формируют определенные нормы и правила выбора. На потребительский выбор также начинают оказывать влияние различные факторы, к ним относятся: индивидуальные особенности человека, его финансовые возможности, уровень культурного развития, выбор первичной и вторичной групп. Социальное взаимодействие индивидов и социальных институтов формирует надындивидуальную действительность, владеющую признаками силового социокультурного поля, которое навязывает свою логику потребительского поведения. После того как сообщение о PR-мероприятии дошло до потребителей, начинают действовать факторы межличностных взаимодействий. Человек не просто воспринимает от рынка те данные, которые были направлены на публику. Эта информация становится объектом активного обсуждения с близкими, друзьями, знакомыми. Стоит отметить, что информация, которая поступает к человеку через сети социальных связей, оказывает большее влияние, чем сигналы, поступающие от рынка. В обсуждении получаемой информации люди обмениваются мнением, делятся своим опытом и вырабатывают социальные оценки потребительских благ и производителей, которые предлагают эти блага обществу [5, с. 54].

Маркетолог Г.А. Васильев считает, что фирма, которая заботится о потребителе, кон- 


\section{СОЦИОЛОГИЯ И СОЦИАЛЬНЫЕ ТЕХНОЛОГИИ}

центрируется на потребностях покупателей, а не на своем товаре. По его мнению, потребители нуждаются больше не в продуктах, а в удовлетворении своих потребностей. Таким образом, рынок определяется не товарами, а нуждами и потребностями общественности $[7$, с. 60].

Исследование потребительского поведения в контексте рекламной деятельности, проведенное в Южно-Уральском государственном университете (г. Челябинск, 2006 г., $n=1200$ ), позволило выявить особенности восприятия студентами, обучающимися на различных направлениях, рекламной информации, а также каналов ее распространения. Для наиболее эффективного воздействия рекламы надо точно знать, по каким каналам и какую информацию необходимо распространять в зависимости от целевой аудитории. Например, на информацию в печатных СМИ и журналах обращает внимание большая часть студентовгуманитариев (67\%), а студенты-техники вообще не обращают внимания на рекламную информацию. При этом студенты обоих направлений специальностей слушают одинаковые радиостанции [12, с. 106]. Данные фокусгрупп, проведенных в рамках исследования влияния коммерческой рекламы на формирование потребительских практик студенческой молодежи (г. Астрахань, 2015 г., $n=200$; фокус-группы $n=16)$, подтвердили выводы анкетного опроса о том, что к наиболее эффективным каналам распространения рекламы относятся интернет-пространство, телевидение и наружные установки. Стоит также отметить, что респонденты утверждали о возрастной направленности того или иного канала распространения рекламы. Так, Интернет был определен респондентами как канал рас- пространения рекламы, в основном направленный на молодежь, в то время как радио или пресса более ориентированы на старшее поколение. Такой канал распространения рекламы, как наружные установки, по мнению участников фокус-групп, направлен на любую возрастную категорию [2, с. 3907].

Исследование влияния PR-деятельности организаций сегмента HoReCa на потребительское поведение (Астрахань, 2017 г., $n=200$; экспертный опрос $n=6$ ) подтвердило гипотезу об эффективности традиционных каналов распространения рекламной информации. В тройку топ-лидеров вошли: интернет, средний балл которого - 4,2 по пятибалльной шкале оценивая, при этом следует отметить, что больше половины респондентов $(54,5 \%)$ оценивают данный канал в 5 баллов. Далее следуют наружные установки, их оценивают в среднем на 3,6 балла, респонденты неоднозначны в своих оценках: 33,3 \% ставят 5 баллов; 25,3 \% - 4 балла и 19,2 \% - 3 балла. Замыкает тройку лидеров телевидение, набрав 3,4 балла. Малоэффективными каналами распространения рекламы оказались радио, общественный транспорт и печатные издания (табл. 1).

Эксперты заявили, что основным PRмероприятием является реклама, которая должна обновляться достаточно часто, так как это влияет на потребительский спрос. Поскольку целевая аудитория - молодежь, то и реклама размещается в основном на простоpax интернета: «Это Вконтакте, это Инстаграм, поэтому такое понятие, как реклама, именно в привычном смысле не используется. Постоянно появляются новые посты, новые афиши и тому подобное. И да, я считаю, что обновление рекламы влияет на потреби-

Таблица 1

Эффективность каналов распространения рекламы

\begin{tabular}{|l|c|c|c|c|c|c|}
\hline \multicolumn{1}{|c|}{ Ответы } & $1^{*}$ & 2 & 3 & 4 & 5 & $\begin{array}{c}\text { Средний } \\
\text { балл }\end{array}$ \\
\hline Телевидение & 10,1 & 16,2 & $\mathbf{2 9 , 3}$ & 18,2 & 26,3 & $\mathbf{3 , 3}$ \\
\hline Печатные издания & 24,2 & $\mathbf{3 5 , 4}$ & 26,3 & 12,1 & 2,0 & 2,3 \\
\hline Радио & 18,2 & 23,2 & $\mathbf{3 9 , 4}$ & 14,1 & 5,1 & 2,7 \\
\hline Интернет & 5,1 & 7,1 & 9,1 & 24,2 & $\mathbf{5 4 , 5}$ & $\mathbf{4 , 2}$ \\
\hline Наружные установки & 8,1 & 19,2 & 14,1 & 25,3 & $\mathbf{3 3 , 3}$ & $\mathbf{3 , 6}$ \\
\hline Общественный транспорт & $\mathbf{2 7 , 3}$ & 22,2 & 26,3 & 16,2 & 8,1 & 2,6 \\
\hline Реклама внутри заведения & 11,1 & 23,2 & $\mathbf{3 1 , 3}$ & 22,2 & 12,1 & 3,0 \\
\hline
\end{tabular}

Примечание. *- 1 - совсем неэффективный канал; 5 - очень эффективный. 
тельский спрос. Так или иначе, нужно постоянно напоминать о себе, иначе все забудут о твоем существовании» (эксперт № 1, администратор бара «Барон»).

Один из экспертов - ведущий социальных сетей - подтверждает данное высказывание и отмечает, что в среднем публикует новости два раза в день. Это количество не надоедает публике, но и позволяет постоянно быть в ленте социальных сетей. Маркетолог ресторана «Subway» считает, что важна не столько частота рекламной информации, сколько само предложение. Если реклама будет выпускаться часто, но предложение не будет интересно целевой аудитории, то реклама никак не сможет повлиять на потребительский спрос. Но все же большинство экспертов отмечают важность частоты выпускаемых рекламных предложений, так как реклама напрямую влияет на востребованность предоставляемых услуг.

По мнению экспертов, во всех организациях сегмента HoReCa есть специальные акции и предложения, которые так или иначе выгодны покупателям. В каждом заведении свои акции, у кого-то это «Третий бургер в подарок», у кого-то это 10 \%-е скидки на дни рождения: «Акций очень много, какие-то из них временные, какие-то остались на постоянной основе из-за своей популярности у аудитории» (эксперт № 3, маркетолог ресторанов быстрого питания «Subway»). Стоит отметить, что акции направлены на основные потребности посетителей: если это бар или кофейня, то скидки направлены на меню; если это развлекательные комплексы, то на мероприятия, развлечения. Исходя из общей концепции развития организации продолжительность акций различна в зависимости от опыта и покупательского спроса: в одних заведениях эти акции носят постоянный характер, другие же стараются ежемесячно обновлять свои предложения.

Информация о PR-акциях в основном размещается в интернет-пространстве, в таких социальных сетях, как ВКонтакте и Инстаграм, поскольку они наиболее популярны в молодежной среде. В режиме онлайн проходят различного рода розыгрыши призов и лотереи, конкурсы, и после их проведения значительно увеличивается количе- ство подписчиков. Никто из экспертов не сказал, что в их заведении проводятся PRакции в реальной жизни, все используют исключительно интернет.

Праздники и различные события - хороший способ привлечь в свое заведение гостей, поэтому ни одна организация, работающая в сегменте $\mathrm{HoReCa}$, не упускает эту возможность, многие проводят различные тематические вечеринки. Стоит отметить, что такие мероприятия пользуются успехом у постоянных посетителей (табл. 2) и привлекают новых: «Мы устраивали тематические вечеринки на Хэллоуин, на Новый Год. Также мы отмечали День Рождения нашего бара. На такие мероприятия достаточно много приходит посетителей. <...> Даже если нет места, люди согласны даже на стоячие места» (эксперт № 2, директор бара «Escobar»); «К большим праздникам, таким как Новый Год, 8 марта, 23 февраля, мы проводим мероприятия. Стараемся устраивать мероприятия именно в тематике праздника... посетителей бывает очень много на таких мероприятиях» (эксперт № 5, арт-менеджер детского центра «Даирчик»); «В честь праздников всегда публикуются поздравительные посты, которые рекламируют мероприятие в заведении. Подписчикам приятно, когда им оказывают внимание» (эксперт № 4, ведущий социальных сетей).

Таблииа 2

\section{Посещение тематических мероприятий (Открытие или День Рождения заведения, тематическая или праздничная вечеринка)

\begin{tabular}{|l|c|}
\hline \multicolumn{1}{|c|}{ Ответы } & $\%$ \\
\hline Да, посещаю & 14,2 \\
\hline Иногда посещаю & 50,8 \\
\hline Посещал(а) один раз & 14,2 \\
\hline Никогда не посещал(а) & 20,8 \\
\hline
\end{tabular}

Исходя из вышесказанного следует то, что в основном учреждения сегмента HoReCa размещают рекламную информацию в Интернете - поистине глобальной информационной, телекоммуникационной сети, что является верным решением, так как большинство респондентов также оценили данный канал распространения информации как самый эффективный. Далее эксперты указали, что обновление рекламы необходимо для того, чтобы 
напоминать о себе на рынке услуг, при этом необходимо разрабатывать новые «выгодные предложения» для привлечения и расширения аудитории.

В целом исследования показали, что реклама как наиболее эффективная часть PRтехнологий активно используется маркетологами организаций сегмента HoReCa, но при этом стоит учитывать социально-демографические характеристики своих целевых аудиторий. Например, часть молодежи лучше воспринимает информацию, размещенную в интернет-пространстве, часть - на телевидении, а кто-то вообще не обращает внимания на рекламу, поэтому стоит задумываться не только о том, где рекламировать свою организацию, но и как.

Таким образом, можно сделать вывод о том, что потребительский выбор в рамках социологического подхода может рассматриваться как социальное действие, осуществляемое на основе нужд индивида, его социальных установок и ценностных ориентаций, зависящих от финансовых возможностей, уровня культуры и социальных образцов потребительского поведения, которые находятся в ближайшем окружении индивида [3, с. 62]. При этом на потребительское поведение воздействуют PR-технологии, которые активно используются различными организациями для привлечения клиентского внимания именно к их товарам и услугам, создание «уникального образа», положительного имиджа, что в свою очередь повышает их конкурентоспособность на рынке потребительских услуг.

\section{СПИСОК ЛИТЕРАТУРЫ}

1. Бодрийяр, Ж. Система вещей / Ж. Бодрийяр. - М. : Рудомино, 2001. - 224c.

2. Бочарникова, И. С. Влияние коммерческой рекламы на формирование потребительских практик студенческой молодежи (на примере Астраханского государственного университета) / И. С. Бочарникова, А. В. Зыгалова // Социология и общество: социальное неравенство и социальная справедливость (Екатеринбург, 19-21 окт. 2016 г.) : материалы V Bсерос. социол. конгр. / отв. ред. В. А. Мансуров. - М. : Российское общество социологов, 2016. - С. 3903-3911.

3. Василенко, И. В. Потребительский выбор в системе социальных практик современного россий- ского регионального населения: основные характеристики и факторы влияния / И. В. Василенко, О. В. Ткаченко // Социология и социальные технологии. -2013 . - № 1. - С. 62-69.

4. Герасимова, Г. И. Связи с общественностью: объектно-предметная область исследования / Г. И. Герасимова // Теория и практика общественного развития. -2010 . - № 4. - С. 41-46.

5. Дорохова, Ю. В. Исследовательские подходы к потребительскому поведению в системе социально-экономических отношений / Ю. В. Дорохова // Социология и жизнь. -2010 . - № 4. - С. 50-56.

6. Киселев, Е. А. Анализ потребительского поведения в контексте стиля жизни современных российских предпринимателей / Е. А. Киселев // Общественные науки. Социология. -2013 . - № 2. - С. 65-71.

7. Киселева, Е. С. Роль и значение потребителя в системе маркетинга и способы управления его поведением на основе соционики / Е. С. Киселева // Известия Томского политехнического университета. - 2008. - № 6. - С. 59-64.

8. Корнеева, Е. И. Институционализация профессии PR / Е. И. Корнеева // Социология. - 2007. № 3-4. - С. 268-279.

9. Леонтьева, Д. С. Public relations как инновационная форма связи бизнеса, власти и общества / Д. С. Леонтьева // Вестник экономики, права и социологии. - 2013. - № 4. - С. 38-40.

10. Радаев, В. В. Социология потребления: основные подходы / В. В. Радаев // Социологические исследования. -2005 . - № 1. - С. 5-18.

11. Черных, Е. A. PR-культура в условиях информационной трансформации современного общества: теоретико-методологические аспекты /Е. А. Черных // Вестник Адыгейского государственного университета. - 2012. - № 2. - С. 135-142.

12. Чуракова, М. В. Изучение потребительского поведения в контексте рекламной деятельности / М. В. Чуракова // Вестник ЮУрГУ. - 2006. - № 8 (63). - C. 104-106.

13. Шамликашвили, В. А. Потребительское поведение в системе социально-экономических отношений / В. А. Шамликашвили // Известия ИГЭА. 2009. - № 4. - C. 98-101.

\section{REFERENCES}

1. Baudrillard J. Sistema veshchey [The System of Objects]. Moscow, Rudomino Publ., 2001. 224 p.

2. Bocharnikova I.S., Zygalova A.V. Vliyanie kommercheskoy reklamy na formirovanie potrebitelskikh praktik studencheskoy molodezhi (na primere Astrakhanskogo gosudarstvennogo universiteta) [Commercial Advertising Influence on the Formation of Students' Consumer Practices (the Case 
of Astrakhan State University)]. Mansurov V.A. ed. Sotsiologiya i obshchestvo: sotsialnoe neravenstvo $i$ sotsialnaya spravedlivost (Ekaterinburg, 1921 oktyabrya 2016 goda): materialy V Vseros. sotsiol. kongressa [Sociology and Society: Social Inequality and Social Justice (Ekaterinburg, October 19-21, 2016): Proceedings of the $5^{\text {th }}$ All-Russian Sociological Congress]. Moscow, Rossiyskoe obshchestvo sotsiologov, 2016, pp. 3903-3911.

3. Vasilenko I.V., Tkachenko O.V. Potrebitelskiy vybor $\mathrm{v}$ sisteme sotsialnykh praktik sovremennogo rossiyskogo regionalnogo naseleniya: osnovnye kharakteristiki i faktory vliyaniya [The Consumer Choice in the System of Social Practices of the Modern Russian Regional Population: Main Characteristics and Factors of Influence]. Sotsiologiya i sotsialnye tekhnologii, 2013, no. 1, pp. 62-69.

4. Gerasimova G.I. Svyazi s obshchestvennostyu: obyektno-predmetnaya oblast issledovaniya [Public Relations: Research Object and Subject Domain]. Teoriya i praktika obshchestvennogo razvitiya, 2010, no. 4, pp. 41-46.

5. Dorokhova Yu.V. Issledovatelskie podkhody $\mathrm{k}$ potrebitelskomu povedeniyu $\mathrm{v}$ sisteme sotsialnoekonomicheskikh otnosheniy [Research Approaches to Consumer Behavior in the System of Social and Economic Relations]. Sotsiologiya i zhizn, 2010, no. 4, pp. 50-56.

6. Kiselev E.A. Analiz potrebitelskogo povedeniya $\mathrm{v}$ kontekste stilya zhizni sovremennykh rossiyskikh predprinimateley [The Analysis of Consumer Behavior in the Context of Lifestyle of Modern Russian Businessmen]. Obshchestvennye nauki. Sotsiologiya, 2013, no. 2, pp. 65-71.

7. Kiseleva E.S. Rol i znachenie potrebitelya $\mathrm{v}$ sisteme marketinga i sposoby upravleniya ego povedeniem na osnove sotsioniki [The Role and Value of the Consumer in the System of Marketing and Ways of Managing Their Behavior on the Basis of Socionics]. Izvestiya Tomskogo politekhnicheskogo universiteta, 2008, no. 6, pp. 59-64.

8. Korneeva E.I. Institutsionalizatsiya professii PR [PR Profession Institutionalization]. Sotsiologiya, 2007, no. 3-4, pp. 268-279.

9. Leontyeva D.S. Public relations kak innovatsionnaya forma svyazi biznesa, vlasti i obshchestva [Public Relations as an Innovative Form of Business, Power and Society Interconnection]. Vestnik ekonomiki, prava $i$ sotsiologii, 2013, no. 4, pp. 38-40.

10. Radaev V.V. Sotsiologiya potrebleniya: osnovnye podkhody [Sociology of Consumption: Main Approaches]. Sotsiologicheskie issledovaniya, 2005, no. 1, pp. 5-18.

11. Chernykh E.A. PR-kultura v usloviyakh informatsionnoy transformatsii sovremennogo obshchestva: teoretiko-metodologicheskie aspekty [Theoretical and Methodological Aspects of the PRCulture in the Conditions of Informational Transformation of Modern Society]. Vestnik $A G U$, 2012, no. 2, pp. 135-142.

12. Churakova M.V. Izuchenie potrebitelskogo povedeniya $\mathrm{v}$ kontekste reklamnoy deyatelnosti [Studying the Consumer Behavior in the Context of Advertising Activity]. Vestnik $\mathrm{YuUrGU}$, 2006, no. 8 (63), pp.104-106.

13. Shamlikashvili V.A. Potrebitelskoe povedenie v sisteme sotsialno-ekonomicheskikh otnosheniy [Consumer Behavior in the System of Social and Economic Relations]. Izvestiya IGEA, 2009, no. 4, pp. 98-101.

\section{Information about the Author}

Irina S. Bocharnikova, Candidate of Sociological Sciences, Associate Professor, Department of Sociology, Astrakhan State University, Tatishcheva St., 20A, 414056 Astrakhan, Russian Federation, omcnk@list.ru.

\section{Информация об авторе}

Ирина Станиславовна Бочарникова, кандидат социологических наук, доцент кафедры социологии, Астраханский государственный университет, ул. Татищева, 20A, 414056 г. Астрахань, Российская Федерация, omcnk@list.ru. 